\title{
Utilisation of eyecare services in an urban population in southern India: the Andhra Pradesh eye disease study
} Rakhi Dandona, Lalit Dandona, Thomas J Naduvilath, Catherine A McCarty,
Gullapalli N Rao

\begin{abstract}
Aim-To assess utilisation of eyecare services by people with visual impairment $<6 / 18$ or equivalent visual field loss in the better eye in the urban population of Hyderabad in southern India.

Methods-2522 subjects of all ages, representative of the population of Hyderabad city, underwent a detailed interview and dilated examination as part of the population based Andhra Pradesh eye disease study. Subjects more than 15 years of age were interviewed regarding the use of eyecare services.
\end{abstract}

Results-Of 250 subjects with presenting distance visual acuity $<6 / 18$ or equivalent visual field loss in the better eye, information on utilisation of eyecare services was available for $229(91.6 \%)$. Of these 229 subjects, $44(19 \%)$ had visual acuity $<6 / 60$ or equivalent visual field loss in the better eye, and $202(88.2 \%)$ had noticed decrease in vision over the past 5 years. Multivariate analysis showed that this decrease in vision was noticed significantly less by subjects with refractive error as the cause of visual impairment (odds ratio 0.34 , $95 \%$ confidence interval $0.12-0.93$ ). Of the 229 subjects who were visually impaired, $108(59 \%)$ did not seek treatment. Multivariate analysis revealed that the odds for seeking treatment were significantly lower for Hindus than Muslims (odds ratio $0.53,95 \%$ confidence interval 0.28 0.98). The reasons for not seeking treatment could be classified as personal $(49.5 \%)$, economic $(30.8 \%)$, and social (19.6\%).

Conclusion-A large proportion of subjects with visual impairment in this urban population in India did not seek treatment even after noticing decrease in vision. Projecting these data to the 155 million urban population $>15$ years of age in India, there may be 4.9 million (95\% confidence interval 4.3-5.5 million) people in urban India who are not seeking treatment for their visual impairment even after noticing decrease in vision. These data suggest that efforts have to be made to better understand the reasons for this phenomenon so that optimal utilisation of the available eyecare services in urban India can be planned.

(Br f Ophthalmol 2000;84:22-27)
Utilisation of eyecare services in simple terms could be defined as accessing the available eyecare services. In the past three decades, utilisation of eyecare services has received some attention in India but has primarily focused on cataract surgery utilisation in rural India where the eyecare services are not as well developed as in urban India. ${ }^{1-3}$

We found $1 \%$ prevalence of blindness (presenting distance visual acuity $<6 / 60$ or central visual field $<20^{\circ}$ in the better eye $)^{4}$ and $7.2 \%$ moderate visual impairment (presenting distance visual acuity $<6 / 12-6 / 60$ or equivalent visual field loss in the better eye $)^{5}$ or $4.8 \%$ moderate visual impairment, if stricter criteria of presenting distance visual acuity $<6 / 18-6 / 60$ or equivalent visual field loss in the better eye are used, ${ }^{5}$ in the urban population of Hyderabad in southern India in the Andhra Pradesh eye disease study. Various causes were responsible for blindness and moderate visual impairment. ${ }^{45}$ Cataract and refractive errors were responsible for a large proportion of blindness and moderate visual impairment. ${ }^{45}$ Both cataract and refractive errors are more easily treatable than the other eye diseases, and appropriate treatment can usually result in good visual recovery.

The urban population studied was that of Hyderabad, a city of 3.5 million people in southern India. Hyderabad has a good network of eyecare facilities which are equally distributed between the government, nongovernmental organisations (not for profit), and private sectors. These facilities include tertiary eyecare hospitals, eye clinics, and opticians. These three groups provide eyecare services ranging from services free of cost to the economically underprivileged, to charges covering cost relating to only the consumables in case of surgery, and charges with profitable margins. An eye examination in Hyderabad could cost $50-200$ rupees $(£ 0.70-£ 2.90)$, and a pair of simple myopic spectacles with an ordinary frame would cost 140 rupees $(£ 2)$.

We assessed the use of eyecare services in this urban population in order to understand the reasons for this burden of visual impairment even with the availability of good eyecare infrastructure for this urban population in India.

Methods

THE ANDHRA PRADESH EYE DISEASE STUDY (APEDS)

APEDS is a population based epidemiology study of 10000 people in four areas represen- 
Subjects with visual impairment

$(n=250)$

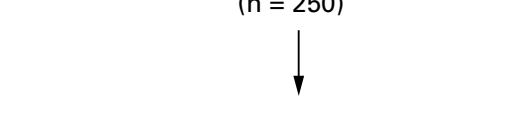

Data available on utilisation of eyecare services

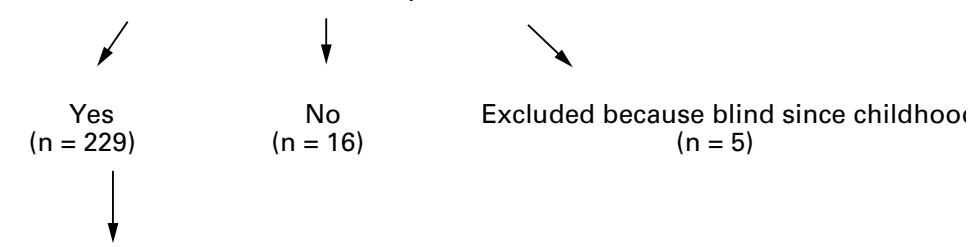

Noticed decrease in vision over the past 5 years

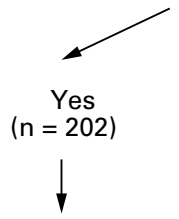

Sought treatment for the noticed decrease

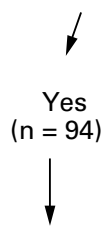

From whom was the treatment sought

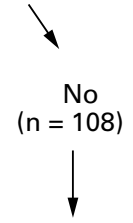

Why

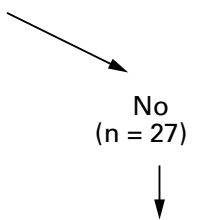

Underwent routine eye examination

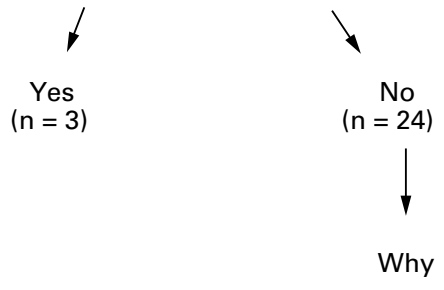

Figure 1 Flow chart showing sequence of questions asked to assess utilisation of eyecare services

tative of the Indian state of Andhra Pradesh. Detailed methodology of APEDS is reported elsewhere. ${ }^{4}$ In brief, the sample size was determined based on the eye diseases of interest with the least assumed prevalence, and the power to detect odds ratios for risk factors. ${ }^{6}$ Subjects $>30$ years of age were oversampled as explained elsewhere and calculation of the estimates was adjusted for this oversampling. ${ }^{46}$ In all, 2954 subjects were sampled for the urban segment of APEDS using a stratified, random, cluster, and systematic sampling strategy. ${ }^{46}$ Subjects were interviewed in detail before the clinical examination. ${ }^{6}$ Written informed consent was obtained before the examination. The urban segment of APEDS was conducted in Hyderabad from October 1996 to June 1997. This study was approved by the ethics committee of the LV Prasad Eye Institute, Hyderabad.

DEFINITION OF VISUAL IMPAIRMENT

Visual impairment was defined as presenting distance visual acuity $<6 / 18$ or equivalent visual field loss in the better eye. For distance visual acuity of $<6 / 60$, the equivalent visual field loss was considered as central visual field $<20^{\circ},{ }^{4}$ and the criteria used for visual field loss equivalent to distance visual acuity $<6 / 18-6 / 60$ are described in detail elsewhere. ${ }^{5}$

USE OF EYECARE SERVICES

Subjects $>15$ years of age responded to a structured questionnaire on use of eyecare services administered by trained field investigators before the clinical examination. ${ }^{6}$ The sequence of questions is represented in Figure 1. Subjects with visual impairment who had sought treatment for the noticed decrease in vision were asked from whom they had sought treatment. The last visit for an eye examination was considered for this question. Subjects with visual impairment who had noticed a decrease in their vision but had not sought eye care, and subjects with visual impairment who had not noticed any decrease in their vision and also had not sought routine eye checkup were asked reason(s) for not seeking treatment. This was an open ended question. The questionnaire contained a list of reasons for not seeking eyecare services. The response given by the subject was marked by the field investigator against the reason on the questionnaire that correlated the most with it. The response given by the subject was documented fully in a separate column if it did not correlate with any of the reasons listed in the questionnaire. All the responses were marked if a subject gave more than one reason for not seeking eyecare services, and the subject was asked to specify the most important reason of all the reasons mentioned, which was then marked with a separate code. These reasons were classified as personal, economic, and social. The reasons directly related to the subject were classified as personal; those relating to family members were classified as social; and those directly related to money were classified as economic reasons. 
CLINICAL EXAMINATION

The clinical examination included measurement of distance and near visual acuity with logarithm of minimum angle of resolution (logMAR) charts, refraction, and a detailed examination of anterior segment, gonioscopy, dilatation, detailed examination of lens, vitreous and posterior segment, and visual fields based on a uniform predefined criteria. $^{4-6}$ Those subjects who were physically debilitated and were unable to come to the clinic were examined at home with portable equipment. ${ }^{6}$

\section{CAUSES OF VISUAL IMPAIRMENT}

If cataract and a posterior segment lesion were present, and removal of cataract would not restore vision, the cause of visual impairment was considered to be the posterior segment lesion. If index myopia caused by cataract was present and even if vision improved with refraction, the cause of visual impairment was considered as cataract and not refractive error. $^{45}$ If a subject had visual impairment from different causes in the two eyes, both were given $50 \%$ weight as the cause of visual impairment. ${ }^{45}$

Table 1 Distribution for noticing change in vision over the past 5 years and for seeking treatment for the noticed change in vision

\begin{tabular}{|c|c|c|c|}
\hline & $\begin{array}{l}\text { Total } \\
(n=229)\end{array}$ & $\begin{array}{l}\text { Number noticed decrease in } \\
\text { vision (\%) }\end{array}$ & $\begin{array}{l}\text { Number sought } \\
\text { treatment (\%) }\end{array}$ \\
\hline \multicolumn{4}{|l|}{ Age (years) ${ }^{\star}$} \\
\hline $16-29$ & 11 & $8(72.7)$ & $1(12.5)$ \\
\hline $30-39$ & 17 & $12(70.6)$ & $5(41.7)$ \\
\hline $40-49$ & 33 & $26(78.8)$ & $12(46.2)$ \\
\hline $50-59$ & 57 & $56(98.2)$ & $21(37.5)$ \\
\hline $60-69$ & 57 & $52(91.2)$ & $28(53.8)$ \\
\hline$\geqslant 70$ & 54 & $48(88.9)$ & $27(56.3)$ \\
\hline \multicolumn{4}{|l|}{ Sex† } \\
\hline Male & 100 & $84(84.0)$ & $37(44.0)$ \\
\hline \multirow{2}{*}{\multicolumn{4}{|c|}{ Education (category) $\ddagger$}} \\
\hline & & & \\
\hline I & 130 & $121(93.1)$ & $56(46.3)$ \\
\hline II & 40 & $32(80.0)$ & $17(53.1)$ \\
\hline III & 33 & $26(78.8)$ & $8(30.8)$ \\
\hline IV & 13 & $12(92.3)$ & $5(41.7)$ \\
\hline V & 9 & $8(88.9)$ & $8(100.0)$ \\
\hline \multicolumn{4}{|c|}{ Socioeconomic status $\rrbracket$} \\
\hline Extreme lower & 30 & $26(86.7)$ & $15(57.7)$ \\
\hline Lower & 91 & $81(89.0)$ & $33(40.7)$ \\
\hline Middle & 96 & $83(86.5)$ & $41(49.4)$ \\
\hline Upper & 6 & $6(100.0)$ & $4(66.7)$ \\
\hline \multicolumn{4}{|l|}{ Religion $\|$} \\
\hline Hindu & 146 & $131(89.7)$ & $53(40.1)$ \\
\hline Muslim & 83 & $71(85.5)$ & $41(57.7)$ \\
\hline \multicolumn{4}{|c|}{ Level of visual impairment } \\
\hline$<6 / 18-6 / 30$ & 124 & $103(83.1)$ & $55(53.4)$ \\
\hline$<6 / 30-6 / 60$ & 61 & $56(91.8)$ & $17(30.4)$ \\
\hline$<6 / 60$ & 44 & $43(97.7)$ & $22(51.2)$ \\
\hline \multicolumn{4}{|c|}{ Cause of visual impairment\# } \\
\hline Cataract & 105 & $97(92.4)$ & $48(49.5)$ \\
\hline Refractive error & 86 & $69(80.2)$ & $24(34.8)$ \\
\hline Others & 38 & $36(94.7)$ & $22(66.1)$ \\
\hline
\end{tabular}

${ }^{\star} \mathrm{p}=0.006$ for noticing decrease in vision and $\mathrm{p}=0.125$ for seeking treatment, $\chi^{2}$ test in univariate analysis.

$t p=0.082$ for noticing decrease in vision and $\mathrm{p}=0.55$ for seeking treatment, $\chi^{2}$ test in univariate analysis.

$\ddagger \mathrm{p}=0.068$ for noticing decrease in vision and $\mathrm{p}=0.015$ for seeking treatment, $\chi^{2}$ test in univariate analysis; Education categories defined as - I: no education, II: class 1-5, III: class 6-10, IV: class 11-12, V: higher than class 12 (including technical courses). Data on education not available for 4 subjects for noticing decrease in vision and for 3 subjects for seeking treatment.

$\S \mathrm{p}=0.76$ for noticing decrease in vision and $\mathrm{p}=0.31$ for seeking treatment, $\chi^{2}$ test in univariate analysis; Socioeconomic status defined according to monthly per capita income in rupees: extreme lower $\leqslant 200$ ( $£ 3.2$ ), lower 201-500, middle 501-2000 and upper >2000. Data on socioeconomic status not available for 6 subjects.

$\| \mathrm{p}=0.54$ for noticing decrease in vision and $\mathrm{p}=0.061$ for seeking treatment, $\chi^{2}$ test in univariate analysis.

$\uparrow \mathrm{p}=0.021$ for noticing decrease in vision and $\mathrm{p}=0.016$ for seeking treatment, $\chi^{2}$ test in univariate analysis.

$\# p=0.080$ for noticing decrease in vision and $p=0.029$ for seeking treatment, $\chi^{2}$ test in univariate analysis.
STATISTICAL ANALYSES

Data were analysed to assess the use of eyecare services by subjects with visual impairment. The demographic associations of use of eyecare services with age, sex, education, socioeconomic status, and religion were assessed. Association of the use of eyecare services was also assessed with severity and cause of visual impairment. The causes of visual impairment were initially categorised as refractive error, cataract, and others. The reasons for not seeking treatment were assessed based on severity of visual impairment. The most important reason was considered for analysis where a subject had given more than one reason for not seeking eyecare services. Five subjects with presenting distance visual acuity $<6 / 60$ were excluded from the analyses because they had visual impairment due to corneal blindness since childhood ${ }^{4}$ and so would not have been expected to notice decrease in vision in the past 5 years.

Analyses were done using the sPSS software (SPSS for Windows, Rel.7.0.0.1995. Chicago: SPSS Inc). Univariate analyses were done followed by multiple logistic regression. The effect of each category of a multicategorical variable was assessed by keeping the first or the last category as the reference. All the variables were introduced in the model simultaneously and none of the variables was optimised. Interactions between the variables in this model were also assessed. Adjustment of the estimates was done for the age and sex distribution of Hyderabad population. ${ }^{7}$ Based on the rates in each cluster, the design effect of the sampling strategy was calculated for the estimates, ${ }^{8}$ and the $95 \%$ confidence intervals adjusted accordingly.

\section{Results}

SUBJECT CHARACTERISTICS

A total of 2522 subjects were interviewed and examined in Hyderabad representing a participation rate of $85.4 \% ; 1859(73.8 \%)$ subjects were more than 15 years of age. In all, 250 subjects presented with distance visual acuity $<6 / 18$ or equivalent visual field loss in the better eye. Of these 250 subjects, data on use of eyecare services were available on $229(91.6 \%)$ subjects of which $129(56.3 \%)$ were females and $131(57.2 \%)$ Hindus.

VISUAL IMPAIRMENT

Of the 229 subjects, 36 (15.7\%) subjects presented with distance visual acuity $<6 / 60$ and eight $(3.5 \%)$ with central visual field $<20^{\circ}$ in the better eye, and $178(77.7 \%)$ presented with distance visual acuity $<6 / 18-6 / 60$ and seven $(3.0 \%)$ with visual field loss equivalent to distance visual acuity $<6 / 18-6 / 60$ in the better eye.

\section{USE OF EYECARE SERVICES}

Of the 229 subjects, 202 (88.2\%) had noticed decrease in their vision over the past 5 years and $27(11.8 \%)$ had not noticed any decrease. The distribution of those who noticed change in vision over the past 5 years is presented in Table 1. On applying multiple logistic 
Table 2 Effect of age, sex, education, socioeconomic status, religion, level of visual impairment, and cause of visual impairment on noticing decrease in vision over the past 5 years and on seeking treatment by multiple logistic regression

\begin{tabular}{|c|c|c|}
\hline & $\begin{array}{l}\text { Odds ratio for noticing } \\
\text { decrease in vision } \\
(95 \% \text { CI) }\end{array}$ & $\begin{array}{l}\text { Odds ratio for seeking } \\
\text { treatment } \\
(95 \% \mathrm{CI})\end{array}$ \\
\hline \multicolumn{3}{|l|}{ Age (vears)* } \\
\hline$<60$ & $1.00(0.37-2.72)$ & $0.57(0.30-1.10)$ \\
\hline$\geqslant 60$ & 1.00 & 1.00 \\
\hline \multicolumn{3}{|l|}{ Sex } \\
\hline Male & 1.00 & 1.00 \\
\hline Female & $2.25(0.85-5.92)$ & $1.55(0.79-3.02)$ \\
\hline \multicolumn{3}{|l|}{ Education $\star$} \\
\hline Literates & 1.00 & 1.00 \\
\hline Illiterates & $1.69(0.61-4.67)$ & $0.75(0.37-1.50)$ \\
\hline \multicolumn{3}{|l|}{ Socioeconomic status ${ }^{\star}$} \\
\hline Extreme lower, lower & 1.00 & 1.00 \\
\hline Middle, upper & $1.03(0.41-2.59)$ & $1.36(0.72-2.57)$ \\
\hline \multicolumn{3}{|l|}{ Religion } \\
\hline Hindu & $0.64(0.26-1.54)$ & $0.53(0.28-0.98)$ \\
\hline Muslim & 1.00 & 1.00 \\
\hline \multicolumn{3}{|l|}{ Level of visual impairment ${ }^{\star}$} \\
\hline$<6 / 18-6 / 60$ & 1.00 & 1.00 \\
\hline$<6 / 60$ & $5.31(0.67-42.06)$ & $1.15(0.55-2.43)$ \\
\hline \multicolumn{3}{|l|}{ Cause of visual impairment ${ }^{\star}$} \\
\hline Other than refractive error & 1.00 & 1.00 \\
\hline Refractive error & $0.34(0.12-0.93)$ & $0.57(0.28-1.16)$ \\
\hline
\end{tabular}

${ }^{\star}$ Categories for these variables combined to increase the power of analysis. Age groups $<60$ and $\geqslant 60$ years combined to assess differences between the non-elderly and elderly groups. Cataract and others combined because both had higher rates than refractive error.

regression (Table 2), the decrease in vision was noticed significantly less by subjects with refractive error as the cause of visual impairment (odds ratio (OR) 0.34, 95\% confidence interval (CI) $0.12-0.93$ ). The odds of noticing decrease in vision were high but did not reach statistical significance for subjects with presenting distance visual acuity $<6 / 60$ or equivalent visual field loss in the better eye (OR 5.31, 95\% CI 0.67-42.06) and for females (OR $2.25,95 \%$ CI $0.85-5.92)$. We did not find a significant association of noticing decrease in vision with age, socioeconomic status, education, and religion. There was no significant interaction between any variables assessed in the multiple logistic regression model.

There was no significant difference in ability to notice decrease in vision between those blind due to visual acuity and those with equivalent visual field loss $(p=1.0$; Fisher's exact test); those with moderate visual impairment due to visual acuity and those with equivalent visual field loss $(p=1.0$; Fisher's exact test); and those with visual impairment due to visual acuity and those with equivalent visual field loss ( $\mathrm{p}=1.0$; Fisher's exact test).
Only 94 of the 229 subjects with visual impairment had sought treatment for the decrease in vision. This translates into only $41.0 \%$ (95\% CI 34.6-47.4\%) utilisation of eyecare services by those with visual impairment. The distribution of those who sought treatment is presented in Table 1. On applying multiple logistic regression (Table 2), the odds for seeking treatment were significantly lower for Hindus than for Muslims (OR 0.53, 95\% CI 0.28-0.98). The odds of seeking treatment were low but did not reach statistical significance for subjects $<60$ years of age (OR 0.57; $95 \%$ CI $0.30-1.10$ ) and for subjects with refractive error as cause of visual impairment (OR 0.57; 95\% CI 0.28-1.16). We did not find a significant association of seeking treatment with sex, socioeconomic status, education, and visual acuity. There was no significant interaction between any variables assessed in the multiple logistic regression model.

Of the 27 subjects who had not noticed any change in vision, $24(88.9 \%)$ had not undergone a routine eye checkup over the last 5 years.

EYECARE PROVIDERS

Data on eyecare provider were missing for three of the 94 subjects who had sought treatment for the noticed change in vision; 87 $(95.6 \%)$ had visited an eye doctor, two $(2.2 \%)$ visited an optician, and two $(2.2 \%)$ visited others.

REASONS FOR NOT USING EYECARE SERVICES For the 108 subjects who did not seek treatment even after noticing a change in vision, the reasons for not seeking treatment could be classified as personal in $49.5 \%$, economic in $30.8 \%$, and social in $19.6 \%$ (Table 3). For those 24 subjects who did not undergo routine eye checkup, the reasons could be classified as personal in $91.6 \%$ and economic in $8.4 \%$.

For the 108 subjects who did not seek treatment even after having noticed a change in vision, the distribution of reasons for not seeking eye care services based on the level of visual impairment is shown in Figure 2.

Table 3 Reasons for not utilising eyecare services

\begin{tabular}{|c|c|c|}
\hline Reason & Category* & No $(\%)+(n=108)$ \\
\hline 1 Do not have a serious problem & $\mathrm{P}$ & $16(15.0)$ \\
\hline 2 Able to see adequately & $\mathrm{P}$ & $10(9.3)$ \\
\hline $\begin{array}{l}3 \text { Eye disease/decrease in vision are natural with growing old, and so do not need } \\
\text { treatment }\end{array}$ & $\mathrm{P}$ & $06(5.6)$ \\
\hline $\begin{array}{l}4 \text { Do not feel comfortable with the eye doctor/general medical practitioner that I have } \\
\text { access to }\end{array}$ & $\mathrm{P}$ & $05(4.6)$ \\
\hline $\begin{array}{l}5 \text { Afraid that seeing someone for eye checkup would reveal vision loss, and therefore } \\
\text { cause worry }\end{array}$ & $\mathrm{P}$ & $04(3.7)$ \\
\hline 6 Have to travel far for eye checkup & $\mathrm{P}$ & $03(2.8)$ \\
\hline 7 Would like eye checkup but other medical problems prevent me from going & $\mathrm{P}$ & $03(2.8)$ \\
\hline 8 Eye checkup not a priority because of other health problems & $\mathrm{P}$ & $02(1.9)$ \\
\hline 9 Do not know where to go for eye checkup & $\mathrm{P}$ & $01(0.9)$ \\
\hline $10 \mathrm{Family} / \mathrm{harvest} / \mathrm{business}$ obligations & $\mathrm{S}$ & $11(10.2)$ \\
\hline 11 No one willing to escort for eye checkup & $\mathrm{S}$ & $07(6.5)$ \\
\hline 12 Dominant person in the family did not feel the need for seeking health care & $\mathrm{S}$ & $03(2.8)$ \\
\hline 13 Do not have money to pay for eye checkup & $\mathrm{E}$ & $33(30.6)$ \\
\hline
\end{tabular}

${ }^{\star} \mathrm{P}=$ personal, $\mathrm{S}=$ social, and $\mathrm{E}=$ economic reason.

tData not available on 4 subjects; percentages do not add up to 100 because of rounding. 


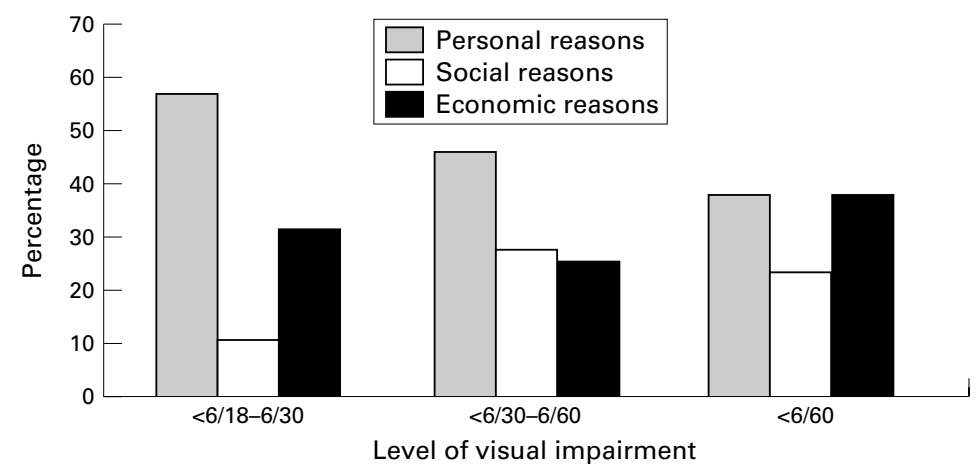

Figure 2 Distribution of reasons for not seeking eyecare services based on the level of visual impairment. probably contributing to underutilisation of eyecare services which, in turn, is leading to undue burden of visual impairment because the majority of the refractive errors are easily correctable with spectacles. This burden of visual impairment due to uncorrected refractive errors in this urban population could be reduced if more people undergo a routine eye examination. In the Indian context, a routine eye examination usually means checking vision and prescribing glasses, and further examination and management if vision with refractive correction is poor. Making vision screening mandatory at different levels, such as school screening to detect visual impairment and when testing for a driving licence, could also help in optimising the utilisation of eyecare services by those with uncorrected refractive errors and those in need of further management could be referred.

In the population studied we found that cataract was the major cause of blindness $(29.7 \%)$ and was responsible for $29.8 \%$ of moderate visual impairment. ${ }^{45}$ The majority of those with cataract as the cause of visual impairment noticed decrease in vision over the past 5 years but only half of them had sought treatment for it. These data suggest that eyecare services for cataract are also not being utilised optimally.

Hindus were less likely to seek treatment for noticed decrease in vision than Muslims. At this stage, it is difficult for us to pin point the reasons for this. However, this translates into a significant underutilisation of eyecare services as $57.7 \%$ of the Hyderabad population is Hindu. ${ }^{9}$ Subjects $<60$ years of age sought treatment less compared with subjects $\geqslant 60$ years of age. This is of importance because people in the younger age group are more likely to be economically productive.

We cannot comment on those variables used in the multivariate model with which we did not find a significant association as the power of the sample to detect associations for these variables was low. We did not find a significant difference in utilisation of eyecare services between the two sexes. However, two of the three studies done in rural India on cataract surgery utilisation have reported that males utilised services more than females. ${ }^{1}{ }^{2}$

The majority of our subjects reported seeking treatment from an ophthalmologist for the noticed decrease in vision. In our questionnaire, the subjects were asked to name the eyecare provider whom they had seen last for the noticed decrease in vision. The questionnaire was not designed to document the type of eyecare provider before the last visit for the noticed decrease in vision if more than one eyecare provider had been consulted. This could have underestimated the role of eyecare providers other than the ophthalmologist as the latter is usually the last in the referral system for an eye problem.

Half of the people cited personal reasons for not seeking treatment even after having noticed decrease in vision followed by economic and social reasons. The predominance of personal reasons probably indicates that awareness ple also sought treatment less compared the others. The less ability to recognise change in vision because of refractive errors is 
regarding the importance of seeking treatment for visual impairment is needed to facilitate utilisation of eyecare services. It is very interesting to note that though $31 \%$ of the reasons cited were economic we did not find a significant relation between socioeconomic status and utilisation of eyecare services. The charge of an eye examination in Hyderabad could range from service free of cost to those who are economically underprivileged to 50200 rupees $(£ 0.70-£ 2.90)$ depending on the eyecare provider. This suggests that better understanding of the economics of utilising eyecare services is needed. Another interesting finding is that social reasons for not seeking eyecare services increased with increase in the level of visual impairment. The reason for this could probably be that with increase in visual impairment, a person becomes more dependent on others around him/her for seeking eyecare services.

Understanding the utilisation of eyecare services is significant because there is considerable burden of disability adjusted life years as a result of the major eye diseases. ${ }^{10}$ These disability adjusted life years are likely to increase with increase in life expectancy. Continuing underutilisation of eyecare services would add to this burden of disability. Our data suggest that there is a need to optimise the utilisation of eyecare services in urban India. Public health strategies which now focus mostly on the eye diseases themselves could be broadened to include improving awareness regarding the treatment of eye diseases and potential benefits of seeking treatment for the decrease in vision. The focus of these strategies should also include refractive errors and other eye diseases, in addition to cataract, for a more comprehensive optimisation of eyecare services. These strategies should have both short term and long term goals. Short term goals should address the potentially easily treatable visual impairment due to refractive error and cataract, and the long term goals should address prevention and early treatment of visual impairment due to corneal disease, glaucoma, and retinal disease. ${ }^{4}$ Increasing awareness and knowledge about eye diseases, and thereby, encouraging people to seek treatment for the decrease in vision could be a part of planning effective and sustainable long term eyecare systems. In addition, economic constraints of the treatment and the other "indirect" costs of seeking eyecare services would have to be understood better to optimise the utilisation of eyecare services.

A recent study of the elderly in London has reported that a large proportion of those with bilateral visual acuity less than $6 / 12$ were not in touch with eyecare services. ${ }^{11}$ Although the definition of visual impairment in this study was more liberal than in ours, it suggests that less than optimal utilisation of eyecare services may also be taking place in the developed country setting.

In conclusion, these data suggest that a large proportion of people with visual impairment in the urban population of Hyderabad in India are not accessing eyecare services. If data from this study are projected to the urban population $>15$ years of age in India, 155 million in $1997,{ }^{12}$ there would be an estimated 10.3 million people with visual impairment, of which 9.1 million people would have noticed decrease in vision over the past 5 years, but a substantial 4.9 million (95\% confidence interval 4.3-5.5 million) people would not have sought treatment for their visual impairment even after having noticed decrease in vision. Better understanding of the reasons for this phenomenon is necessary to develop public health strategies which target eye diseases as well as people to optimise the utilisation of eyecare services.

This study was supported by the Hyderabad Eye Research Foundation, Hyderabad, India. Rakhi Dandona is supported in part by the RB McComas scholarship from the University of Melbourne. The authors gratefully acknowledge Professor Hugh R Taylor of the University of Melbourne for guidance in design of APEDS; and VN Naidu, Pyda Giridhar, Kovai Vilas, and MNKE Prasad for interviewing the subjects.

1 Gupta SK, Murthy GVS. Where do persons with blindness caused by cataracts in rural India seek treatment and why? Arch Ophthalmol 1995;113:1337-40.

2 Brilliant GE, Lepkowski JM, Zurita B, et al. Social determiBrilliant GE, Lepkowski JM, Zurita B, et al. Social determi-
nants of cataract surgery utilisation in south India. Arch Ophthalmol 1991;109:585-9.

3 Venkatswamy G, Brilliant GE. Social and economic barriers to cataract surgery in rural south India: a preliminary report. F Visual Impairment Blindness 1981;Dec:405-8.

4 Dandona L, Dandona R, Naduvilath TJ, et al. Is current eye-care-policy focus almost exclusively on cataract adequate to deal with blindness in India? Lancet 1998;351: 1312-6.

5 Dandona L, Dandona R, Naduvilath TJ, et al. Burden of moderate visual impairment in an urban population in southern India. Ophthalmology 1999;106:497-504.

6 Dandona R, Dandona L, Naduvilath TJ, et al. Design of a population-based study of visual impairment in India: the Andhra Pradesh Eye Disease Study. Indian $f$ Ophthalmol 1997;45:251-7.

7 Chief Planning Officer, Hyderabad. Handbook of statistics Hyderabad district 1993-94. Hyderabad, India, 1994

8 Bennett S, Woods T, Liyanage WM, et al. A simplified general method for cluster-sample surveys of health in developing countries. World Health Stat Quart 1991;44:98106.

9 Directorate of Census Operations, Andhra Pradesh. Census of India 1991, Andhra Pradesh: religion. New Delhi: Government of India, 1995.

10 Murray CJL, Lopez AD. Global mortality, disability, and the contribution of risk factors: Global Burden of Disease
Study. Lancet 1997;349:1436-42.

11 Reidy A, Minassian C, Vafidis G, et al. Prevalence of serious eye disease and visual impairment in a north London population: population based cross sectional study. BMF 1998;316:1643-6.

12 The World Bank. India-new directions in health sector development at the state level: an operational perspective. New Delhi: World Bank, 1997. 